\title{
Impact of climate change on wave energy resource: The case of Menorca (Spain)
}

\author{
J.P. Sierra*, M. Casas-Prat ${ }^{\#}$ and E. Campins, \\ Laboratori d'Enginyeria Marítima,Universitat Politècnica de Catalunya, Jordi Girona 1-3, Mòdul D1, Campus \\ Nord, 08034 Barcelona, Spain
}

Centre Internacional d'Investigació dels Recursos Costaners, Jordi Girona 1-3, Mòdul D1, Campus Nord, 08034 Barcelona, Spain

\#Now at Environment and Climate Change Canada, Toronto, Canada
*joan.pau.sierra@upc.edu; tel. +34 934016467; fax: +34 934011861

\begin{abstract}
The aim of this paper was to analyse how changes in wave patterns, due to the effect of climate change, can affect wave energy power and yield around Menorca (NW Mediterranean Sea). The present and future wave energy conditions were derived from recently developed high-resolution wave projections in the NW Mediterranean. These wave projections were forced by surface wind fields obtained, respectively, by 5 different combinations of global and regional circulation models (GCMs and RCMs) for the A1B scenario. The results showed that the projected future spatial and directional distributions of wave energy are very similar to those of the present conditions. The multimodel ensemble average illustrated a slight general decrease in the annual and seasonal wave power (except for summer). However, the inter-model variability is large since two models showed opposite trends to the other 3 in most cases. Such inter-model variability is lower(higher) for winter(autumn). Another result is the reduction of the temporal variability in the future, considering both the multi-model mean and each single model projection. Such a decrease is consistent with the future seasonal redistribution of energy throughout the year. This would entail an increase in the efficiency of wave energy converters deployed in this area due to the more regular temporal distribution of the energy.
\end{abstract}

Keywords: Wave energy, Climate change, Menorca Island, Balearic Islands, Wave energy converter

\section{Introduction}

Wave energy appears to be one of the most promising alternatives to fossil fuels and one of the most environmentally friendly since it could contribute to reduce greenhouse gas emissions. It is expected that over the next decades wave energy conversion will undergo significant advances in research, design and testing [1] due to the rising demand of renewables in energy supply [2].

In general, research on wave energy production focuses on locations that have high energy potential. In addition, wave energy is particularly appropriate for many islands because they receive 
a large amount of this resource and are usually highly dependent on external energy sources. For this reason, wave energy potential has been assessed on various islands in the Atlantic Ocean, including the Canary Islands [3-6], Madeira [7] and the Azores [8]; in the Pacific Ocean, on islands such as Hawaii [9-10] and Taiwan [11]; in the Caribbean Sea [12]; and even in the Mediterranean Sea [13-14]. In the Mediterranean area, although the wave energy potential is modest, wave energy production could still be economically viable [15] and many technical issues related to extreme sea climate probably could be solved more easily [14-15].

In order to accurately predict the long-term energy resource and yield for a wave farm, it is essential to take natural variability and climate change into account [16]. However, few studies have addressed the impacts of climate change on wave energy resource. Some examples are [17-19], in which the uncertainty in predicted energy yield resulting from uncertainty in future wave conditions has been estimated. More recently, the impact of climate change on wave energy generation has been investigated based on numerical wave modelling driven by past/present wind fields and future wind scenarios associated with different levels of greenhouse gas emissions [16].

This paper focuses on the assessment of wave power potential and wave energy yield around Menorca, an island in the Spanish Mediterranean Sea. This assessment is carried out based on the present and future wave projections developed by [20], following an approach similar to that used in [16]. Nevertheless, in [16] only one combination of Global Circulation Models (GCMs) and Regional Circulation Models (RCMs) was used for two scenarios (A1B and B1), while in this study five combinations of GCMs and RCMs are used for the A1B scenario. The use of several models allows to assess the inter-model variability, one of the largest factors of uncertainty in climate change projections.

The remainder of the manuscript is structured as follows. Section 2 briefly describes the study area. Section 3 presents the available data and the methodology used. The wave power resource and wave energy yield for present conditions in the study area, including their spatial distribution and seasonal variations, are assessed in Section 4. Section 5 focuses on the climate change signals. Finally, the conclusions of the paper are presented in Section 6.

\section{Study area}

The study area, Menorca, is located in the northwestern Mediterranean Sea (39.81-40.09 $\mathrm{N}, 3.79$ $4.32^{\circ} \mathrm{E}$ ) and forms part of the Balearic Islands (see Figure 1). It has a surface area of $701.8 \mathrm{~km}^{2}$ and a population of about 100,000 inhabitants, mainly concentrated along the coast. The island was declared a Biosphere Reserve in 1993.

The study area has been selected based on: (i) the availability of data, (ii) the high wave energy potential in the area located between the Balearic Islands and western coast of Sardinia in comparison with the rest of the Mediterranean Sea [14-15] and (iii) the low (2\%) current percentage of electric energy extracted from renewable sources in the island (two solar facilities and one wind farm) [14].

The present climate in the Mediterranean basin is dominated by extra-tropical cyclones [21] formed via baroclinic instability, which is higher during the winter season [22]. In this season, one of the most active areas of cyclogenesis is the Gulf of Genoa, generating some local features like the Tramontana and Mistral winds (intense and persistent N and NW winds), which are channeled and intensified through the valleys between mountain ranges existing on the NW Mediterranean. Moreover, the climate is affected by moving depressions generated either in the Atlantic Ocean or in northwestern Europe [23]. Additionally, many subregional and mesoscale effects take place in this area producing large spatial and seasonal variability [24]. The reduced scale of the basin, along with its peculiar features (complex orography and the moisture of a relatively large mass of water) makes the Mediterranean climate more difficult to predict than climates in other places [21]. 


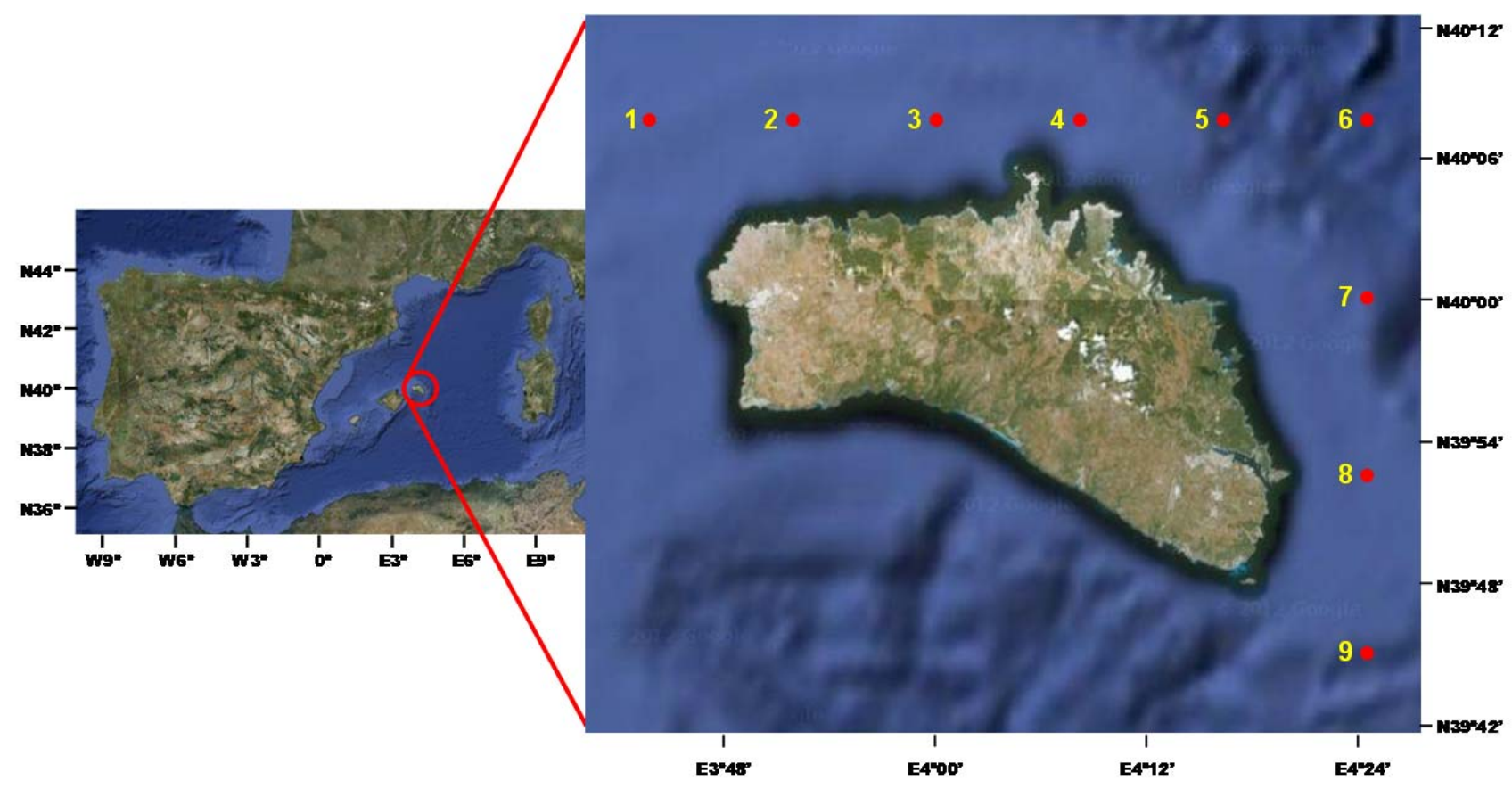

Fig. 1. Location of the study area (left panel) and the analyzed points (right panel).

In summer seasons, thermal and orographic effects, like the temperature contrasts between land and sea, play a greater role in the genesis and maintenance of cyclones which are mainly located in the Gulf of Genoa and over the Iberian Peninsula [24]. During summer seasons, the Mediterranean is also exposed to tropical systems [25] as a result of its location in a transitional zone between humid mountains in the north and arid regions in the south. From a climatic point of view, spring and autumn are transitional periods between winter and summer [25].

Concerning the future climate, it is very difficult to know exactly how the aforementioned atmospheric patterns will react to climate change due to the many competing processes that interact [20]. Many studies have found a consistent poleward shift of the location of extratropical cyclones [21] which, at the European scale, would be translated into enhanced wind speeds over northern Europe, and a decrease in southern Europe [26-27] where the study area is located. As a result of this and other factors like sea surface temperature (SST) gradients and concentration of water vapor in the atmosphere most studies concur that there will be a decrease in the number of Mediterranean cyclones [20]; however, there is a lack of consensus on whether the number of intense cyclones will increase or decrease $[25,28]$.

Regarding the variation in wind direction, the analysis of the results of model simulations suggest that the predominant westerly flow over Europe will be significantly enhanced, whereas the cyclonic weather type (large cyclone located over central Europe associated with above-average wind speed over the Mediterranean Sea) is expected to decrease [29]. Nevertheless, it is relevant to point out that there is a large uncertainty, even larger than for the wind speed, since some models exhibit contrasting patterns (i.e. enhance of easterly flow instead).

The aforementioned generally expected weakening of storms in the future Mediterranean climate will in turn entail a major reduction of the significant wave height (Hs), especially during winter. However, a probable increase in wind intensity in the Gulf of Genoa could lead to higher waves locally and in a few nearby coastal stretches [20]. Future wave climate during the summer clearly shows different patterns compared to winter, which is reasonable due to the different processes involved in the atmosphere. During this season, the tendency of the median Hs to increase is more 
extended than in winter, which is explained by an increase of the wind velocity. In general, the intermodel variability is large, especially in winter between projections driven by different GCMs. For example, the different evolution of W-E major scale winds produced by GCMs seems to lead to significant differences in the distribution of the sea-swell waves because it is aligned with the larger fetch [20].

\section{Data and methods}

\subsection{Available wave data}

As explained in the Introduction, this study uses the wave projections developed by [20], which consist of five wave data sets of two 30-year periods (1971-2000 for the "present", and 2071-2100 for the "future"), with a time resolution of $3 \mathrm{~h}$ and a spatial resolution of $0.125^{\circ}$. These data were obtained using the SWAN wave model [30] forced by wind projections generated with 5 combinations of global (GCMs) and regional circulation models (RCMs) obtained for the A1B scenario from the $4^{\text {th }}$ Assessment Report from IPCC [31]. Four European institutes provided the atmospheric data: DMI (Danmarks Meteorologiske Institut, Denmark), KNMI (Koninklijk Nederlands Meteorologisch Instituut, The Netherlands), MPI (Max-Planck-Institut für Meteorologie, Germany) and SMHI (Sveriges Meteorologiska och Hydrologiska Institut, Sweden), the latter providing 2 sets of atmospheric data. As in [20], in this study the data sets are named with acronyms relative to the combination of RCM and GCM used for their obtaining, as shown in Table 1. For further details, please refer to [20].

\begin{tabular}{|c|c|c|c|}
\hline Model acronym & Institute & GCM & RCM \\
\hline HIR_E & DMI & ECHAM5 & HIRHAM5 \\
\hline RAC_E & KNMI & ECHAM5 & RACMO2 \\
\hline REM_E & MPI & ECHAM5 & REMO \\
\hline RCA_E & SMHI & ECHAM5 & RCA3 \\
\hline RCA_H & SMHI & HadCM3Q3 & RCA3 \\
\hline
\end{tabular}

Table 1. Models used for obtaining wave projections.

From the aforementioned wave projections, 9 wave grid points are selected for this study (see Figure 1), which correspond to the North and East sides of Menorca. This selection is based on the study of [14] which showed that these areas are those with larger wave energy potential.

\subsection{Methods}

The points selected from the wave model grid to assess the wave energy resource around Menorca are plotted in Figure 1. They are located in deep water (water depths between 200 and $500 \mathrm{~m}$ except at point 6 , with a depth greater than $3000 \mathrm{~m}$ ) and therefore they are not affected by wave refraction and diffraction. The theoretical wave power at any point can be thus obtained using the following deep-water expression:

$$
P=\frac{\rho g^{2}}{64 \pi} H_{s}^{2} T_{e} \simeq 0.491 H_{s}^{2} T_{e}
$$


where $P$ is the wave power per unit of crest length $(\mathrm{kW} / \mathrm{m}), H_{s}$ is the significant wave height, $\rho$ is the density of seawater (assumed to be $1025 \mathrm{~kg} / \mathrm{m}^{3}$ ) and $g$ is the gravitational acceleration. The energy period $T_{e}$ can be computed as a function of spectral moments of order $0\left(m_{0}\right)$ and $-1\left(m_{-1}\right)$ as follows:

$$
T_{e}=\frac{m_{-1}}{m_{0}}
$$

However, as pointed out in [32], measured sea states are often specified in terms of significant wave height $H_{s}$ and either peak period $T_{p}$ or mean period $T_{z}$. The energy period $T_{e}$ is rarely specified and must be estimated from other variables when the spectral shape or the spectral moments are unknown, as in this case. One approach when $T_{p}$ is known is to assume the following:

$$
T_{e}=\alpha T_{p}
$$

where $\alpha$ is a coefficient whose value depends on the shape of the wave spectrum $(0.86$ for a Pierson-Moskowitz spectrum and increasing towards unity with decreasing spectral width) [32]. Taking into account that wave spectra in this area are rather wide $[14,20]$, as suggested by $[32,33]$ a value of $T_{e}=0.9 T_{p}$ is used to assess the wave energy resource.

With Equations (1) and (3) and using the data described in Section 3.1, the present/future 30-year time series of the total wave energy resource associated to each RCM-GCM combination (5 in total) is obtained for each grid point of Figure 1. In addition, the power average is computed not only for the whole dataset but also as a function of the wave direction, obtaining, respectively, the total energy potentially available and the directional distribution of the wave power. Note that the latter is especially important when converting wave energy with non-point absorber devices.

Besides the amount of wave energy, temporal variability at different time scales (daily, monthly and seasonal) is also an important parameter to assess the energy resource. This resource is usually characterized by a significant variability throughout the year. In estimating the power performance of a WEC it is fundamental to take into account this variability; indeed, an estimate based on mean annual values may well result in a wrong decision making [34]. When selecting the location for wave energy converters (WEC), sites with steady wave energy flux are preferable to those with unsteady wave conditions because they are more reliable and show a greater efficiency.

In Figure 2 the $H_{s}$ time series of the five models corresponding to a year (1989) and a point (\#2) randomly selected are shown to illustrate this seasonal variation. There we can see how the highest waves are concentrated in the first part of the year (days 1 to 90) corresponding to winter, followed by autumn (days 284 to 365). In summer (days 192 to 283) the lowest $H_{s}$ are observed. Nevertheless, the time series corresponding to model RCA_E shows an atypical behavior, with a similar energetic content along the year and highest waves during the last month (December). This atypical distribution of wave heights is consistent with the results obtained for this model and shown below. 

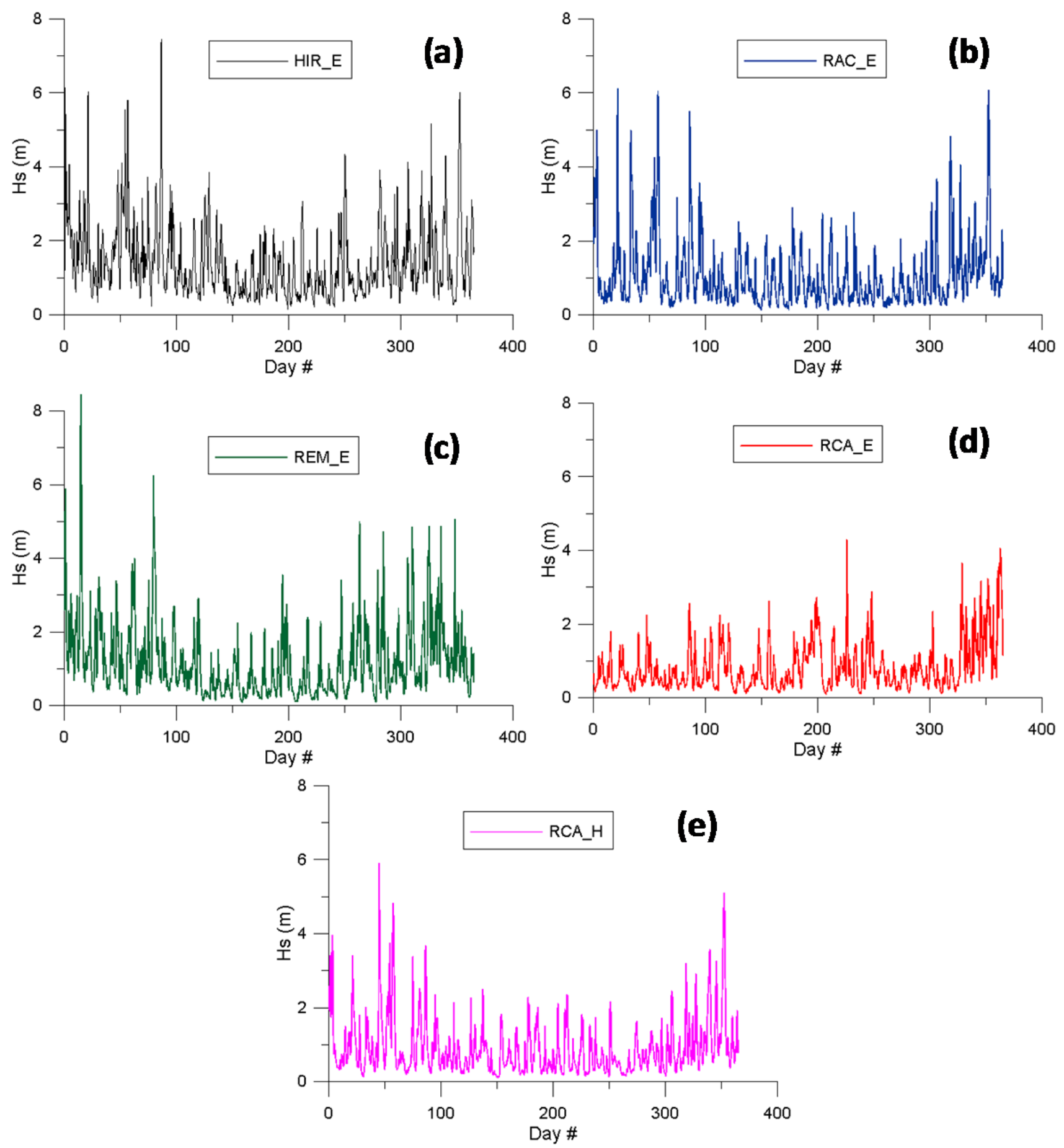

Fig. 2. Example of $\mathrm{Hs}$ annual time series for the 5 models in a year and a point randomly selected: 1989 and point 2 .

Apart from the seasonal and monthly distribution, to better assess the effect on the temporal variability at a specific location we use the coefficients proposed by [32]: the seasonal variability index (SV) and the monthly variability index (MV). The SV is defined as follows: 


$$
S V=\frac{P_{s 1}-P_{s 4}}{P_{\text {year }}}
$$

where $P_{S 1}$ is the mean wave power for the highest-energy season (usually winter) and $P_{S 4}$ is the mean wave power for the lowest-energy season (usually summer), and $P_{\text {year }}$ is the annual mean wave power. The greater the value of SV, the larger the seasonal variability, with values lower than 1 indicating moderate seasonal variability.

MV is defined as follows:

$$
M V=\frac{P_{M 1}-P_{M 12}}{P_{\text {year }}}
$$

where $P_{M 1}$ is the mean wave power for the highest-energy month and $P_{M 12}$ is the mean wave power for the lowest-energy month. Obviously, the values of MV are greater than those of SV.

An assessment of the amount of electric energy delivered by two models of WECs (Pelamis [35] and Wave Dragon [36]) under the present and future wave conditions is performed. These two devices have been selected because their development state can be considered mature [37] and have been used in a number of studies [e.g. 7, 14, 37-40]. Note that the output energy of a WEC depends not only on the available wave energy but also on the distribution of such energy as a function of the significant wave height and the wave energy period. In other words, the efficiency to extract wave energy depends on the value of $H_{s}$ and $T_{e}$. Such efficiency is machine-dependent and it is actually specified in the power matrix associated to the device. For each energy bin, defined by a certain interval of $H_{s}$ and $T_{e}$, the power matrix indicates the corresponding energy output. The power matrices for the two devices can be found in [7].

Finally, one aspect not considered in the paper but that can be very important is the analysis of the potential changes in the nearshore wave conditions generated by the presence of a wave farm, as shown in [41-42]. This point should be carefully assessed before WEC deployment.

\section{Present situation}

\subsection{Potential wave power and energy}

Figure 3 shows the annual average wave power at each location for the present situation corresponding to the five RCM-GCM combinations involved. The corresponding values for the annual wave energy are detailed in Table 2. Both wave energy power and annual wave energy have the same order of magnitude as in other studies [14-15] for the multi-model ensemble and for models RAC_E and REM_E (although for REM_E they are slightly lower). On the contrary, RCA_E and RCA_H greatly underpredict the wave energy, whereas HIR_E clearly gives excessive values. Regarding the spatial distribution, the points with a higher potential $(6,5,9)$ are those corresponding to the NE and SE "corners" of the island, being the multi-model mean power larger than $7.5 \mathrm{~kW} / \mathrm{m}$, which corresponds to an average annual wave energy between 64.8 and $71.9 \mathrm{MW} \mathrm{h}$ (See Table 2). 


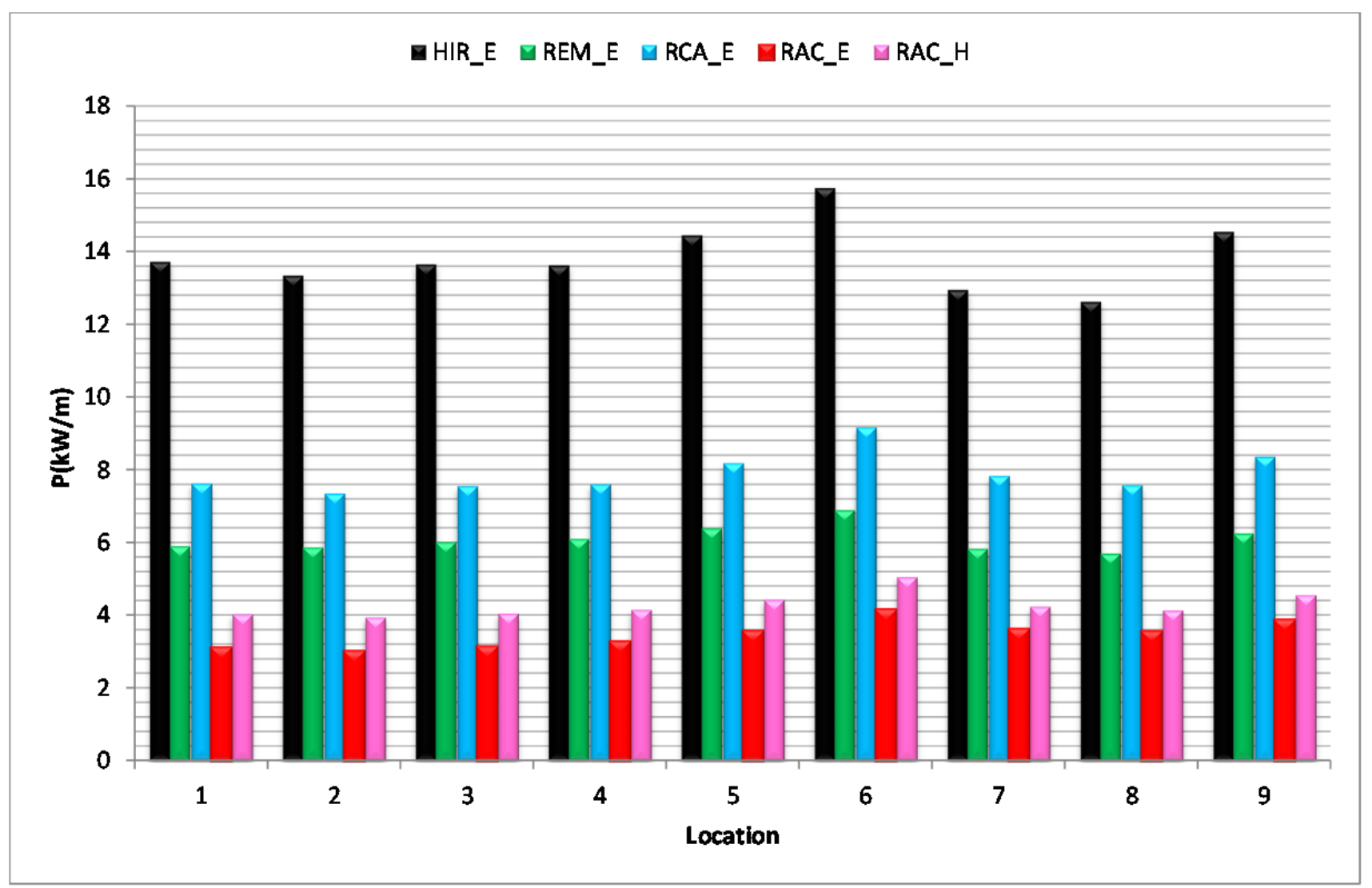

Fig. 3. Annual average wave power at the 9 study points for each data set and for the present situation (1971-2000).

\begin{tabular}{cccc|ccc}
\hline \multicolumn{7}{c}{ Annual Wave Energy-Present (MW h) } \\
\hline \multirow{2}{*}{ Point } & \multicolumn{7}{c}{ Data Set } \\
\cline { 2 - 7 } $\mathbf{1}$ & HIR_E & REM_E & RAC_E & RCA_E & RCA_H & Average \\
$\mathbf{2}$ & 120.19 & 51.68 & 66.75 & 27.24 & 35.30 & 60.23 \\
$\mathbf{3}$ & 116.86 & 51.33 & 64.39 & 26.46 & 34.51 & 58.71 \\
$\mathbf{4}$ & 119.57 & 52.65 & 66.14 & 27.51 & 35.39 & 60.25 \\
$\mathbf{5}$ & 119.31 & 53.44 & 66.58 & 28.73 & 36.35 & 60.88 \\
$\mathbf{6}$ & 126.58 & 55.98 & 71.66 & 31.27 & 38.72 & 64.84 \\
$\mathbf{7}$ & 137.97 & 60.36 & 80.33 & 36.44 & 44.24 & 71.87 \\
$\mathbf{8}$ & 113.44 & 51.07 & 68.59 & 31.71 & 37.14 & 60.39 \\
$\mathbf{9}$ & 110.55 & 49.93 & 66.40 & 31.19 & 36.18 & 58.85 \\
\hline
\end{tabular}

Table 2. Present annual wave energy at the 9 study points for each data set.

Wave power and wave energy results have therefore a notable uncertainty due to associated large inter-model variability. For example, HIR E gives values (12.5 to $16 \mathrm{~kW} / \mathrm{m})$ of wave power about twice that of RAC_E (7.5 to $9 \mathrm{~kW} / \mathrm{m})$ and REM_E (5.8 to $6.8 \mathrm{~kW} / \mathrm{m})$ and about four times that of 
RCA_E (3 to $4 \mathrm{~kW} / \mathrm{m}$ ) and RCA_H (4 to $5 \mathrm{~kW} / \mathrm{m}$ ). This large range of responses is reasonable taking into account the discrepancies already encountered in terms of the wave climate (e.g. [20]), which are in turn exaggerated due to the non-linearity of Eq. (1). [20] obtained a large overestimation of the median $H_{s}$ for HIR_E due to the RCM used, being the least energetic results associated to RCA_E and RCA_H due to a spatial averaging process in the wind obtaining. Therefore, the over(under)estimation of the wave power/energy can be mainly explained by the over(under)estimation of the $H_{s}$. However, sometimes the wave period has also a relevant role that explains why the least energetic model in terms of the median of $H_{s}\left(R C A \_H\right)$ is not the one with the lowest wave power.

\subsection{Directional average power}

Apart from the total amount of wave energy, it is important to consider the distribution of wave energy among wave directions and how each location is exposed to them. By averaging the directional wave power distribution of the five analyzed models, we observe that the East and Northeast directions provide the largest values (see radial charts in Figure 4). At the points located at the NE corner of the island the East waves are the most energetic (points 5 and 6) while in the NW and SE corners of the island (points 1, 2 and 9) the NE waves provide larger power. The remaining points show a similar diagram, with these two directions containing most of the wave energy in a similar proportion.

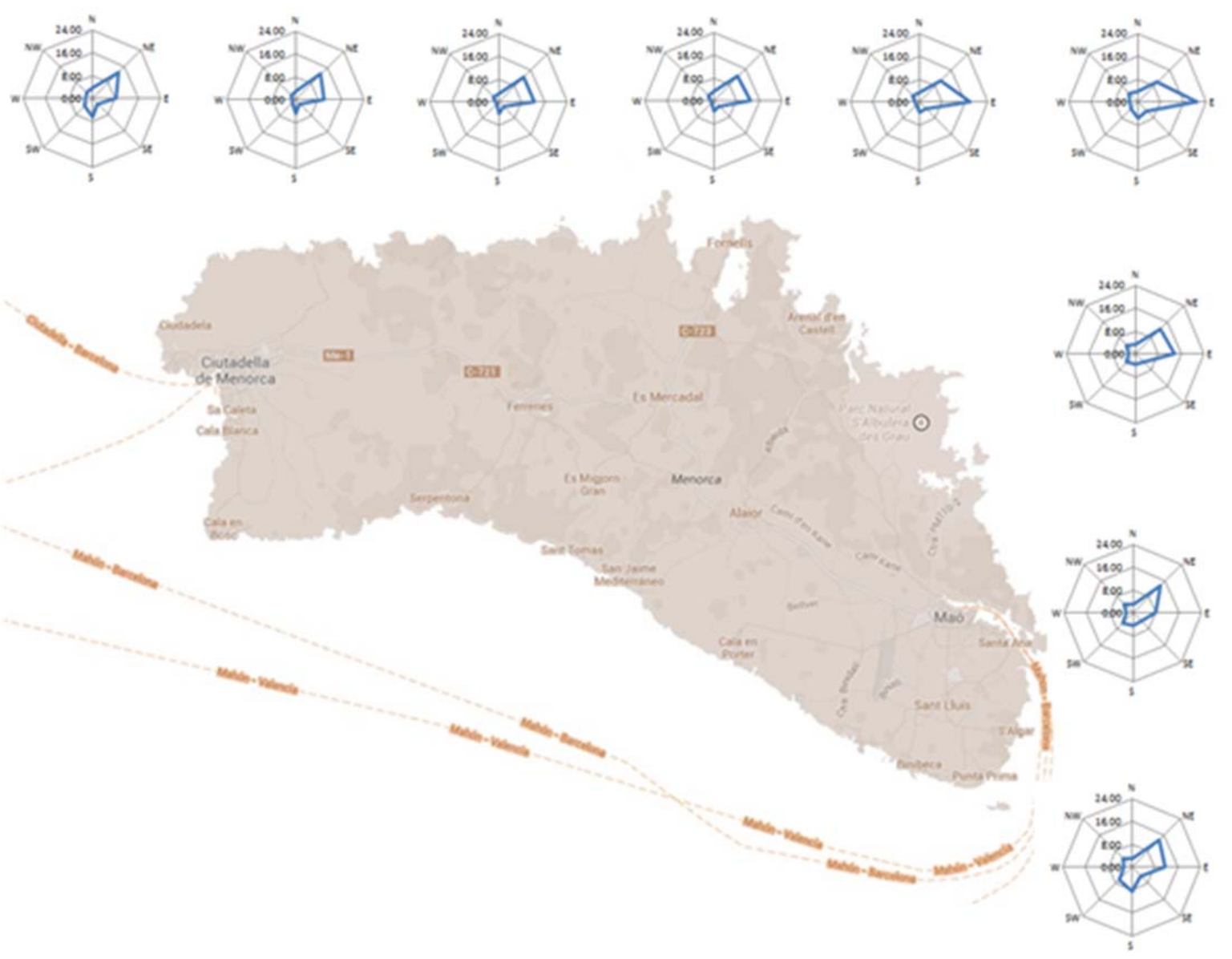

Fig. 4. Present directional average power distribution at the study points (model ensemble). 


\subsection{Temporal variability}

Figure 5 and Table 3 illustrate, respectively, the monthly and seasonal distribution of wave power. The obtained temporal distribution of wave power shows the strong seasonal character of Menorca's wave energy, with a considerable range of variation among seasons, as observed in previous studies [14]. Higher power months are focused in the winter season, tripling or quadrupling the values of the summery months. All models, except the RCA_E, follow a similar pattern.

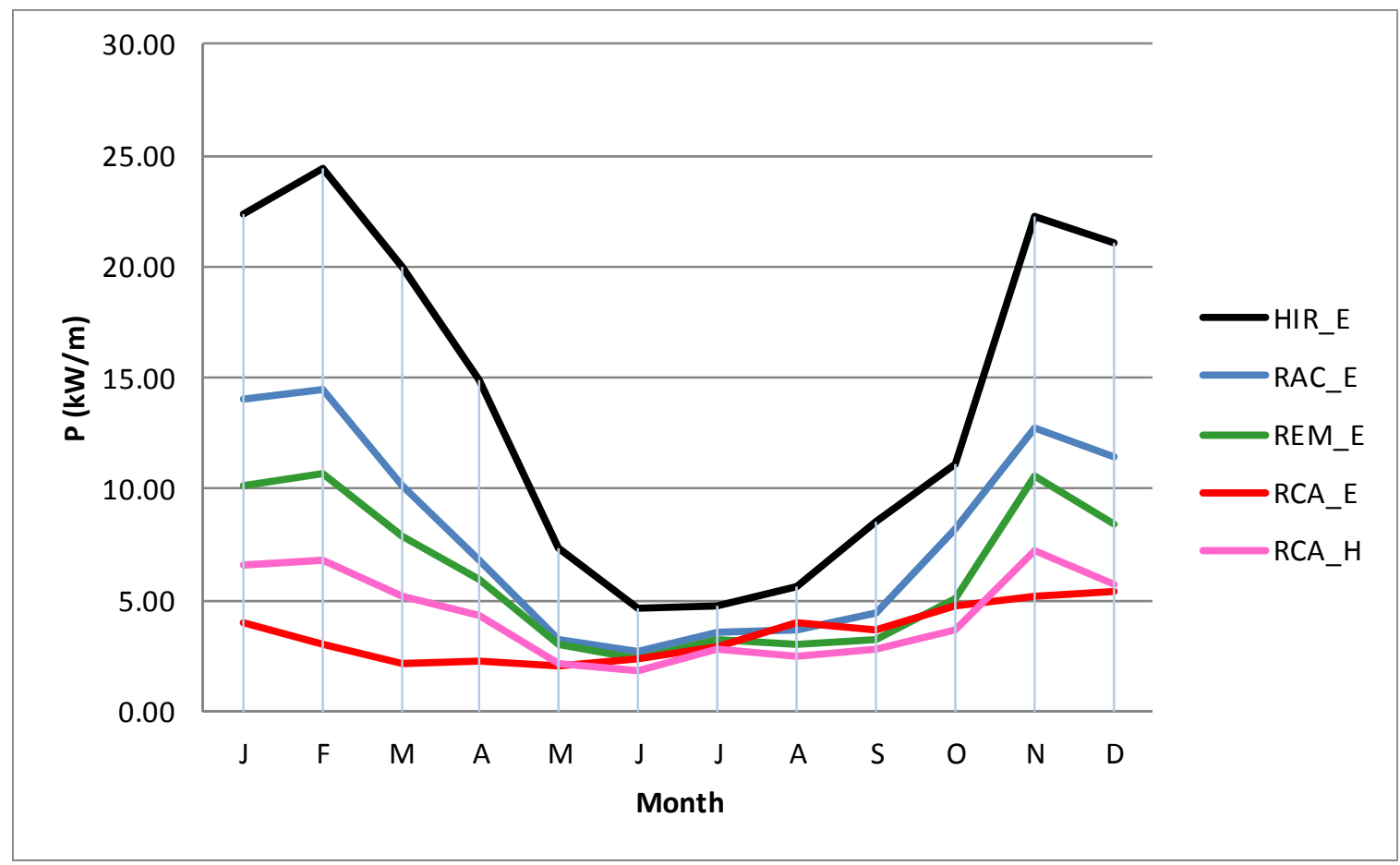

Fig. 5. Present monthly average wave power for each data set.

\begin{tabular}{|c|c|c|c|c|}
\hline Point & Winter & Spring & Summer & Autumn \\
\hline $\mathbf{1}$ & $11.06(3.73,22.87)$ & $6.14(1.86,13.55)$ & $3.08(2.29,4.72)$ & $7.36(4.12,14.01)$ \\
\hline $\mathbf{2}$ & $10.74(3.67,22.23)$ & $6.03(1.81,13.44)$ & $2.99(2.08,4.51)$ & $7.16(4.00,13.44)$ \\
\hline $\mathbf{3}$ & $10.94(3.82,22.58)$ & $6.22(1.90,13.87)$ & $3.13(2.20,4.69)$ & $7.34(4.13,13.73)$ \\
\hline $\mathbf{4}$ & $10.94(3.98,22.37)$ & $6.30(2.02,13.87)$ & $3.26(2.33,4.83)$ & $7.40(4.28,13.66)$ \\
\hline $\mathbf{5}$ & $11.60(4.31,23.55)$ & $6.75(2.23,14.85)$ & $3.50(2.51,5.16)$ & $7.89(4.62,14.52)$ \\
\hline $\mathbf{6}$ & $12.79(4.95,25.44)$ & $7.49(2.64,16.08)$ & $3.93(2.81,5.79)$ & $8.75(5.37,15.97)$ \\
\hline $\mathbf{7}$ & $10.48(4.28,20.02)$ & $6.37(2.31,13.52)$ & $3.44(2.42,5.21)$ & $7.39(4.53,13.28)$ \\
\hline $\mathbf{8}$ & $10.35(4.19,19.77)$ & $6.25(2.27,13.08)$ & $3.26(2.27,4.97)$ & $7.14(4.32,12.90)$ \\
\hline $\mathbf{9}$ & $12.18(4.56,24.45)$ & $6.97(2.45,14.57)$ & $3.29(2.23,4.98)$ & $7.76(4.59,14.48)$ \\
\hline
\end{tabular}

Table 3. Present seasonal distribution (average and range of variation among the 5 models) of wave power $(\mathrm{kW} / \mathrm{m})$. 
With respect to the seasonal distribution (Table 3 ), we can observe the large variability among models, in particular in winter (with wave power varying from 4.7 to 6.1 times between the most and the less energetic models) and especially in spring (with ratios from 5.8 to 7.4). On the contrary, the seasonal inter-model variability is considerably lower in summer, with wave powers for the most energetic models that only double those of the less energetic ones, and in autumn (variations between 2.9 and 3.4). The average (of the five models) indicates that 39\% of Menorca's annual wave power corresponds to winter, $23 \%$ to spring, $12 \%$ to summer and $26 \%$ to autumn. These values are very similar at those found in previous studies [14], where a respective distribution per seasons of $42 \%, 24 \%, 8 \%$ and $26 \%$ was reported.

As mentioned before, the coefficients SV and MV are indicative of the temporal variability. Figure 6 shows the values of these variability coefficients, considering the average among the 5 models and their values for each model that show the range of variation. There are large differences among the 5 models, being HIR_E and REM_E those with larger temporal variability, while RCA_E is that presenting the lowest values for both coefficients. On the other hand, the spatial variability of these coefficients is small, with similar values for each model and the average, showing no clear preferred location regarding temporal variability. We can also conclude that, in general, the obtained variability is in average lower than the observed in previous works [14] in this area, where the estimated variability was similar to the upper values obtained here.
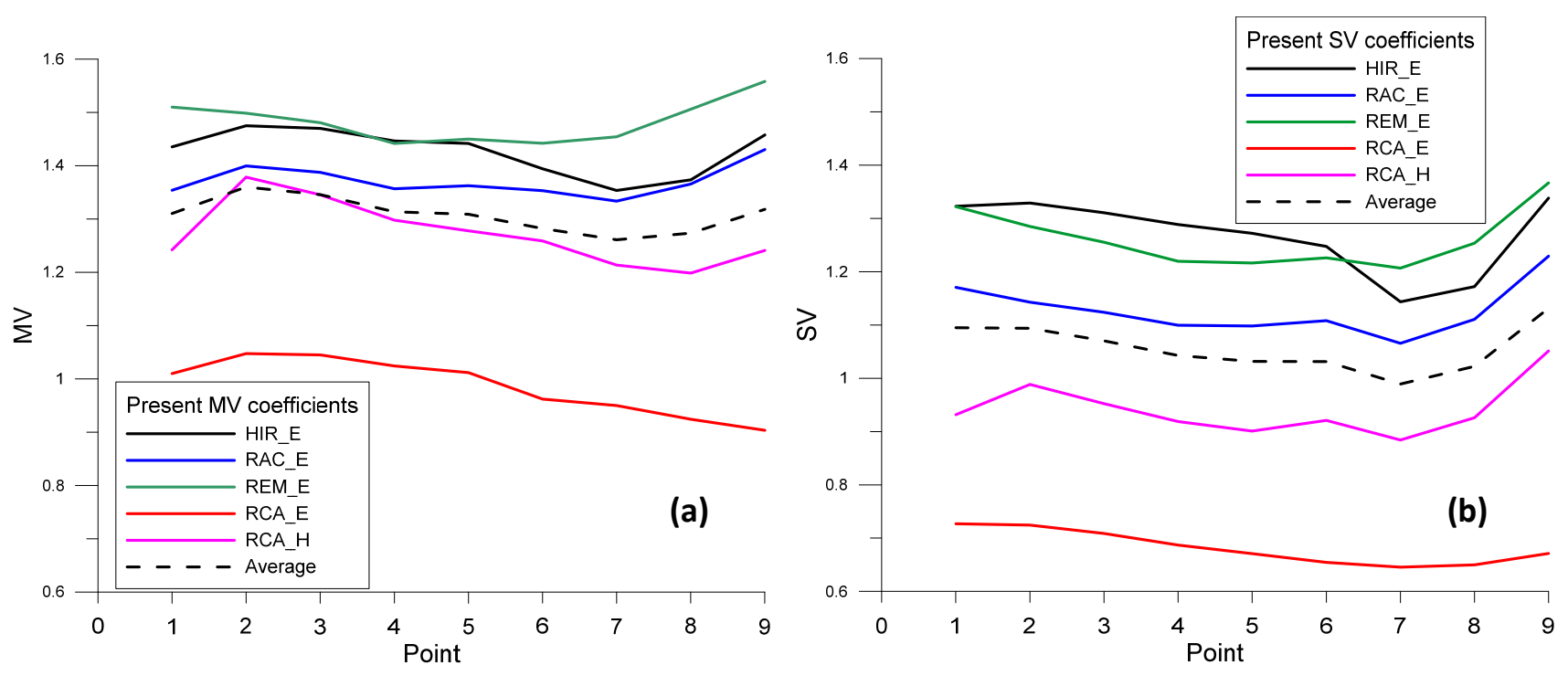

Fig. 6. Present coefficients of temporal variability. (a): MV coefficient. (b): SV coefficient.

\subsection{Wave energy output}

As explained in Section 3, the wave energy resource is finally evaluated by means of the power output that would be obtained with 2 different WECs: Pelamis [35] and Wave Dragon [36]. The Pelamis is an attenuating WEC while the Wave Dragon is an overtopping type device. Figure 7 shows the results for the present conditions for the multi-model ensemble and each model separately. The largest wave energy output is located in the northeast part of the island (points 6 and 5), as observed in previous studies [14]. However, a close value of energy is observed at the SE corner too (point 9). In terms of the average, the order of magnitude is in general in agreement with [14] for both WECs. However, again there is a great dispersion among models, following the pattern obtained for the wave power and annual energy: overprediction for HIR_E and underprediction for RCA_E and RCA_H, being the results of RAC_E and REM_E similar to the 
outputs of [14]. Notice that the Wave Dragon output is one order of magnitude greater than that from Pelamis due to its greater power $(7000 \mathrm{~kW}$ vs $750 \mathrm{~kW})$.
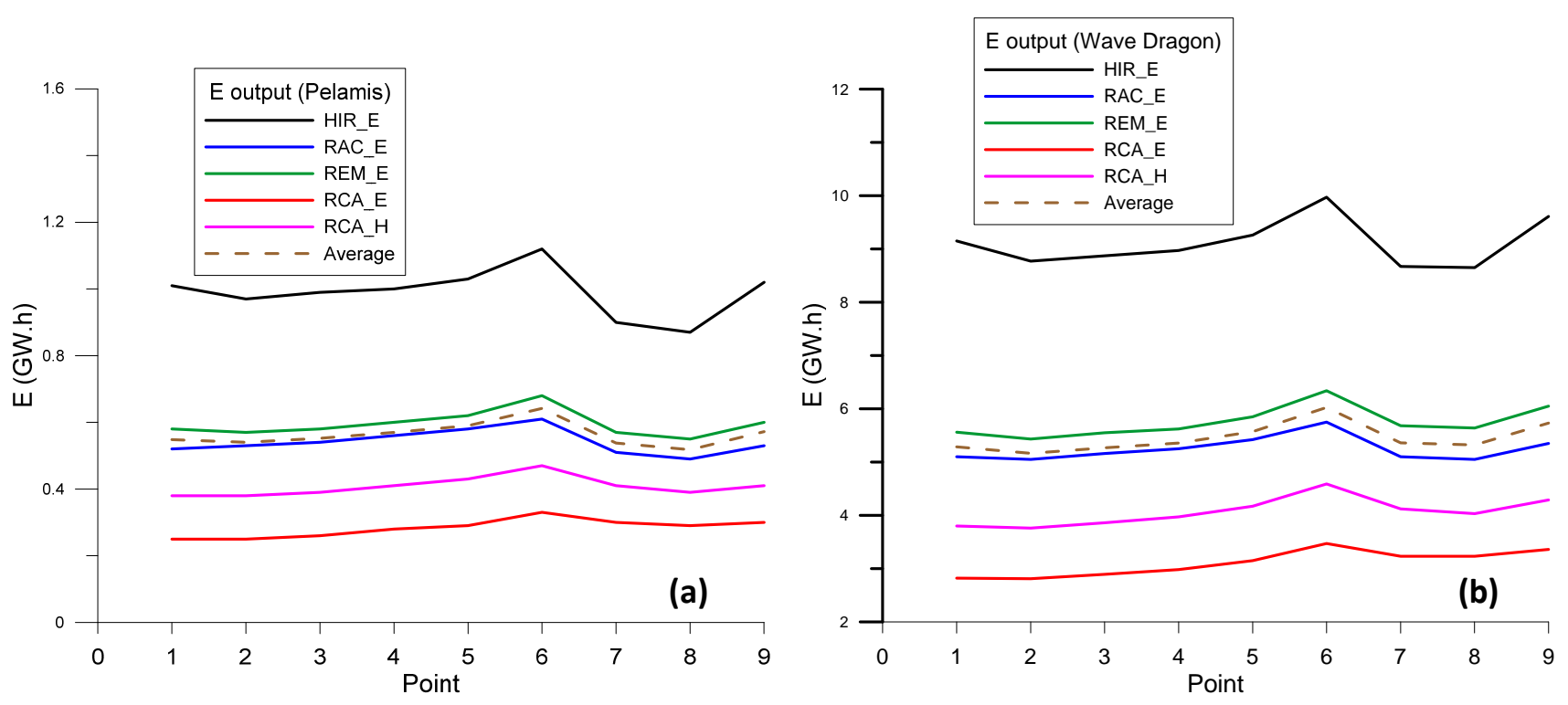

Fig. 7. Present energy output from the two selected devices for the 5 models and their average.

\section{Effect of climate change on wave power}

Figure 8 illustrates the variation of potential wave energy at each point and for each model between present and future conditions. The variation has been computed as the difference between future and present wave energy divided by the present one. In general, we can see how three models (HIR_E, REM_E and RCA_E) clearly give lower future wave energy, while the other two (RAC_E and RCA_H) project larger future wave energy. The 3 models predicting a wave energy reduction have higher rates of change (decreases greater than $5 \%$ ) and, in particular, RCA_E projects a decrease between $10 \%$ and $15 \%$. On the contrary, the 2 models projecting a rise in the future wave energy have a rate of change lower than $5 \%$ and even one of them (RCA_H) projects slight reductions in the SE corner of the island (points 8 and 9). This gives an ensemble average of wave energy reduction between $2.5 \%$ and $6 \%$. The opposite trends illustrate that the large uncertainty is not only observed in the present conditions but also in the climate change signal. 


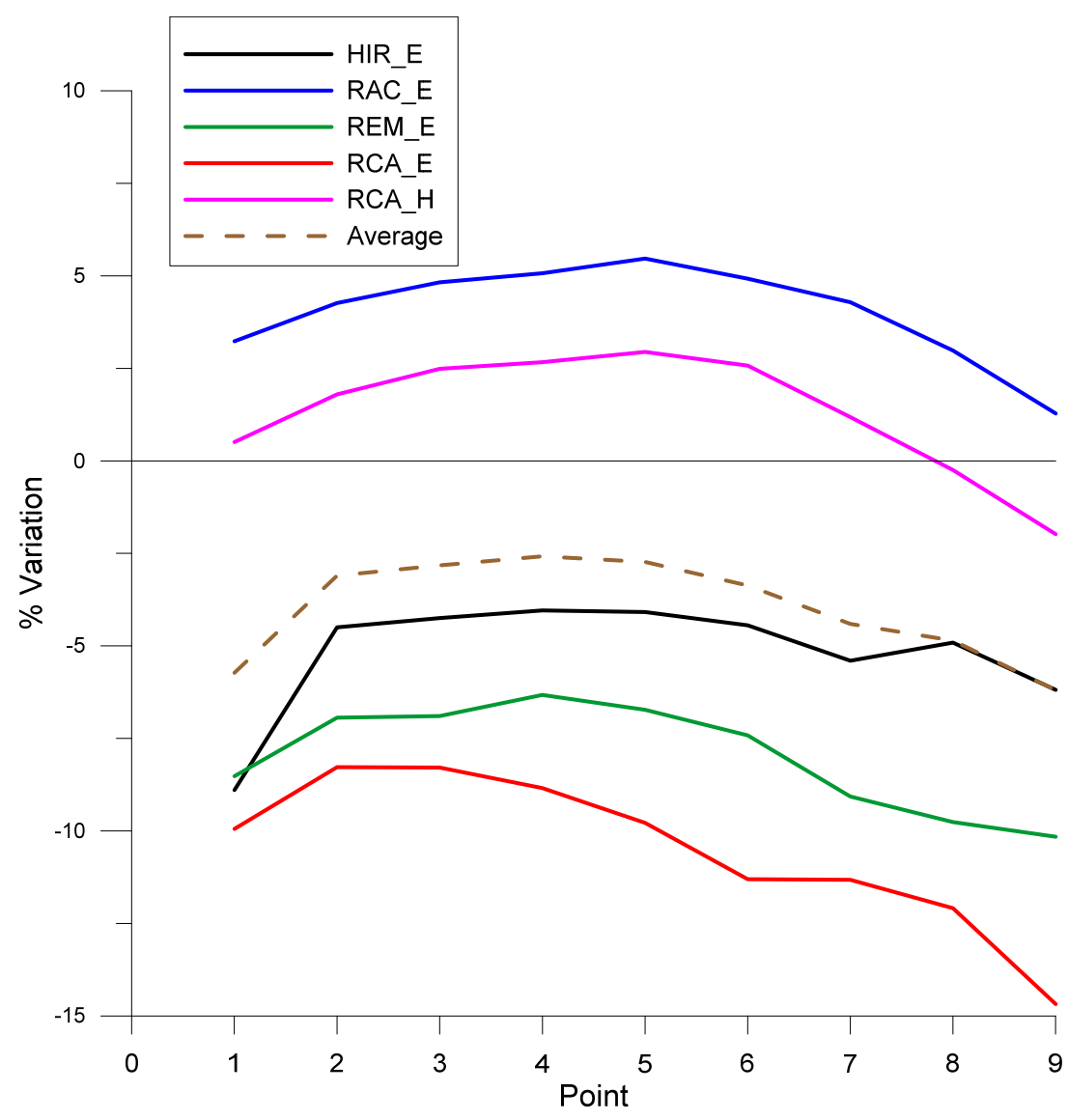

Fig. 8. Wave energy variation (\%) in future conditions with respect to the present at each point and for each model. Positive values indicate future increases of wave energy, while negative values reflect future decreases in the wave resource.

To illustrate the relationship between changes in wave energy and changes in wave conditions and to better understand the inter-model variability, the changes in the wave energy are discussed with respect to the wave climate, mainly $H_{s}$ and $T$. According to [43], the error of the wave heights and periods predicted with the SWAN numerical model is about $10 \%$. In Figure 9, the changes in wave height and wave period corresponding to mean conditions (the medians $H_{50}$ and $T_{50}$ ) and to extreme conditions (the $95^{\text {th }}$ percentiles $H_{95}$ and $T_{95}$ ) have been plotted. The 3 models projecting future energy decrease (HIR_E, REM_E and RCA_E) present lower values of wave height and period for both the median and the $95^{\text {th }}$ percentile (i.e. mean and extreme wave conditions) at all locations (with one exception, the $T_{95}$ for HIR_E at point 8, although with an increase lower than 1\%). On the contrary, the 2 models projecting a higher energetic potential (RAC_E and RCA_H) show increases of wave height and period corresponding to storm conditions $\left(H_{95}\right.$ and $\left.T_{95}\right)$ and different behavior in the less energetic waves $\left(H_{50}\right.$ and $\left.T_{50}\right)$. Thus, RCA_H shows lower future values of both mean parameters (except the period for point 5 which has a small increase, lower than 1\%). For model RAC_E the future mean wave periods are larger while wave heights do not show significant changes (variations of $0 \%$ in 6 points or around 1\% in the other 3 points). Therefore, for both models, the future increase of wave energy potential is due to the most energetic waves, indicating that these models project a future increase in the storminess around the island.

Concerning the wave directionality, the predominant and most powerful direction is $E$ followed by NE (Figure 4), and both situations (present and future) have the same pattern of wave directional distribution. 

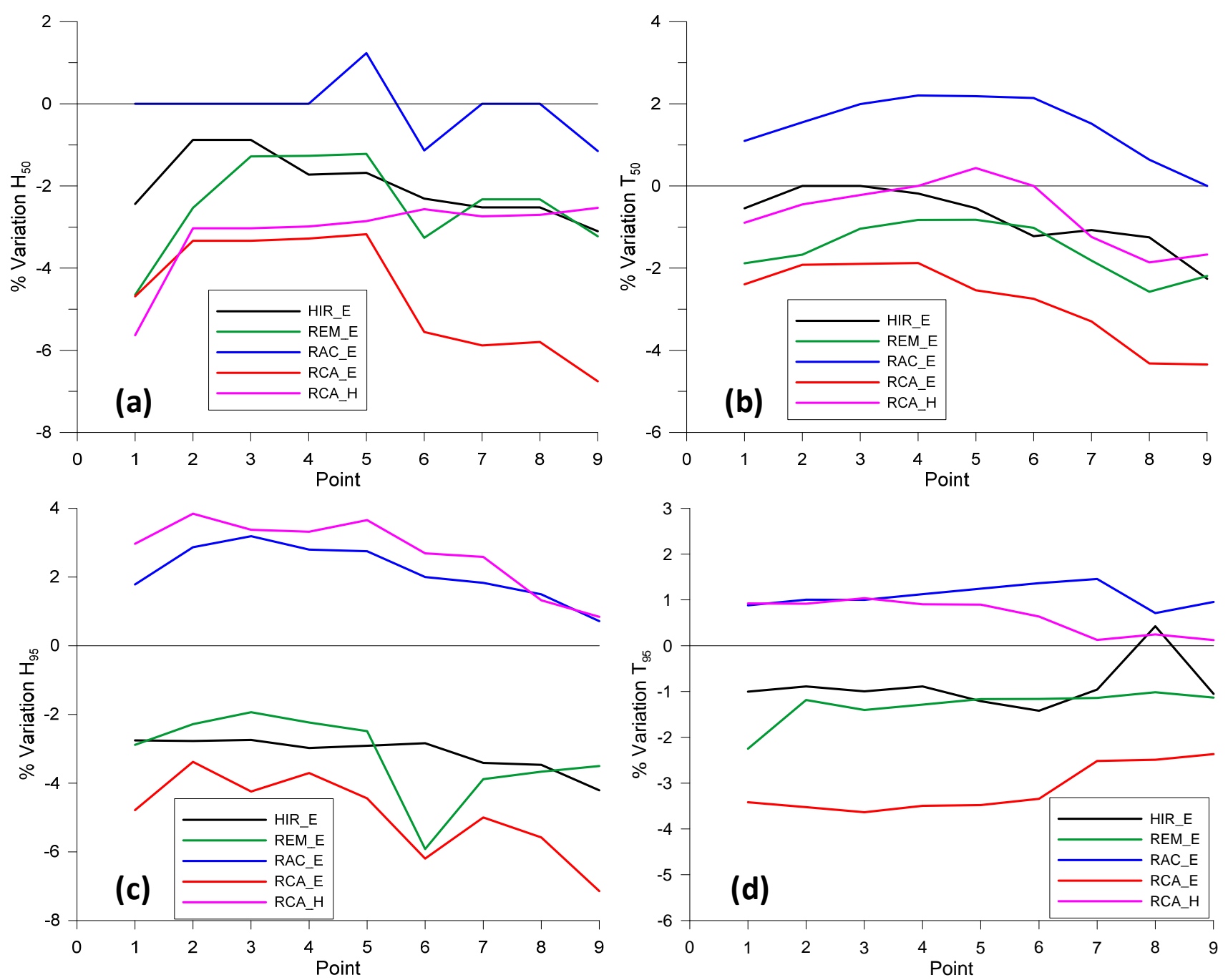

Fig. 9. Variation (in \%) of wave parameters in future conditions with respect to the present at each point and for each model. $\mathrm{H}_{50}$ (a) and $\mathrm{T}_{50}$ (b) are respectively the median of the wave height and period. $\mathrm{H}_{95}(\mathrm{c})$ and $\mathrm{T}_{95}$ (d) are respectively the $95^{\text {th }}$ percentile of the wave height and period.

The climate change signal in the seasonal wave energy distribution (Figure 10) is also analyzed. The ensemble average shows a clear future reduction in winter and autumn (between $4 \%$ and $6 \%$ depending on the location). During spring the ensemble also projects a decrease but to a lesser extent (lower than 3\%), except in the SE corner of the island (-5.9\%). In contrast, in summer there is more spatial variability, with a tendency to increase the energy in the northern part of the island (up to 3.3\%) whereas in the $E$ the negative trend (as for the other seasons) is maintained. Nevertheless the inter-model variability is very large, as shown in Figure 10, where the range of variation for the different models is also presented. The season with a lower inter-model variability is winter, for which all the models project future reductions, except RAC_H in the northern part of the island (points 1 to 6) with small increases (lower than 1\%, except in point 1 with an increase of 2.4\%). In spring 2 models project energy decreases (RAC_E and in particular HIR_E) and 3 increases (REM_E, RCA_E and RCA_H, being the last one that with larger rises). In summer 2 models predict increases (REM_E and in particular HIR_E) and 3 decreases (RAC_E, RCA_H and in particular RAC_E). Finally, autumn is the season showing a larger inter-model variability, with 3 models projecting energy decreases (HIR_E, RAC_E and especially RCA_E with reductions greater than $20 \%$ ) and 2 energy increases (RCA_H -around 2\%- and REM_E -around 10\%). 


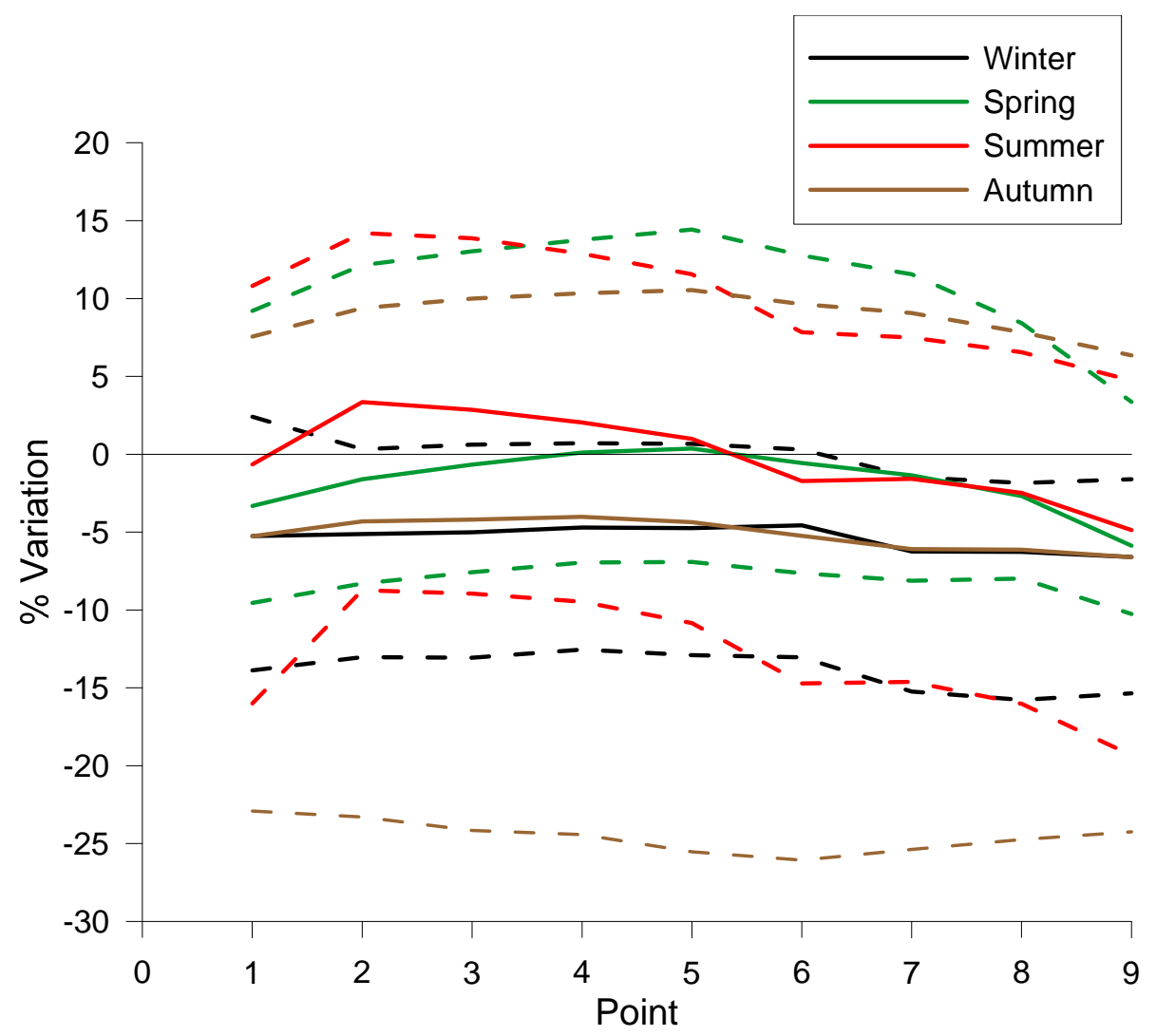

Fig. 10. Wave energy variation (\%) in future conditions with respect to the present at each point and for each season (average of the 5 models and range of variation). Positive values indicate future increases of wave energy, while negative values reflect future decreases in the wave resource. Solid lines correspond to average values and dashed lines to the ranges of variation.

Continuing with the temporal variability analysis (an important factor in terms of energy efficiency), the variation between future and present values of coefficients MV and SV has been analyzed (as shown in Figure 11). Both coefficients will decrease significantly in the future, considering either the multi-model mean or the range of variation. The lower temporal variability is consistent with the future seasonal redistribution of energy throughout the year observed in Figure 10 (decrease of energy during the most powerful seasons like winter and increase during the milder ones like summer). This result would favor the deployment of WECs, since their wave energy yield would be more regular along time. 

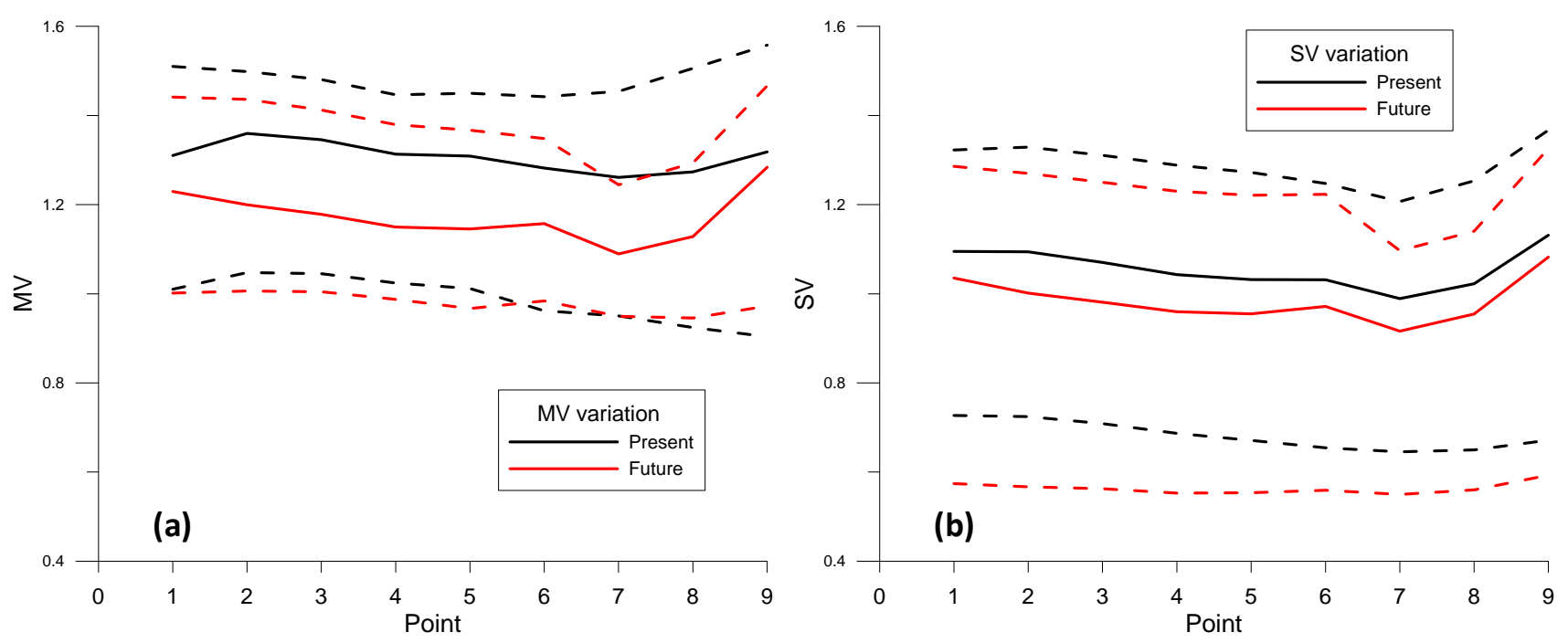

Fig. 11. Present and future values (average of the 5 models and range of variation) of coefficients MV and SV at the nine points. Solid lines indicate average values and dashed lines the ranges of variation.

Finally, the change of the wave energy output given by two WECs (Pelamis and Wave Dragon) is also analyzed (Figure 12). As it could be expected, this evolution (for each model and at each point) almost mimics (with little variations due to the particular characteristics of each WEC) the wave energy evolution (Figure 8). Pelamis energy output shows a slightly larger variability among models, with greater increases and decreases (in percentage). This is probably due to the fact that Wave Dragon offers its better performance at wave periods between 10 and $15 \mathrm{~s}$ [7], while Pelamis gives the maximum output at wave periods between 6.5 and $11.5 \mathrm{~s}$ [7], being these last range more frequent in the Mediterranean Sea. Therefore many waves observed in the area fall in the most energetic range of Pelamis and as a consequence this device is more sensitive to changes in wave parameters.
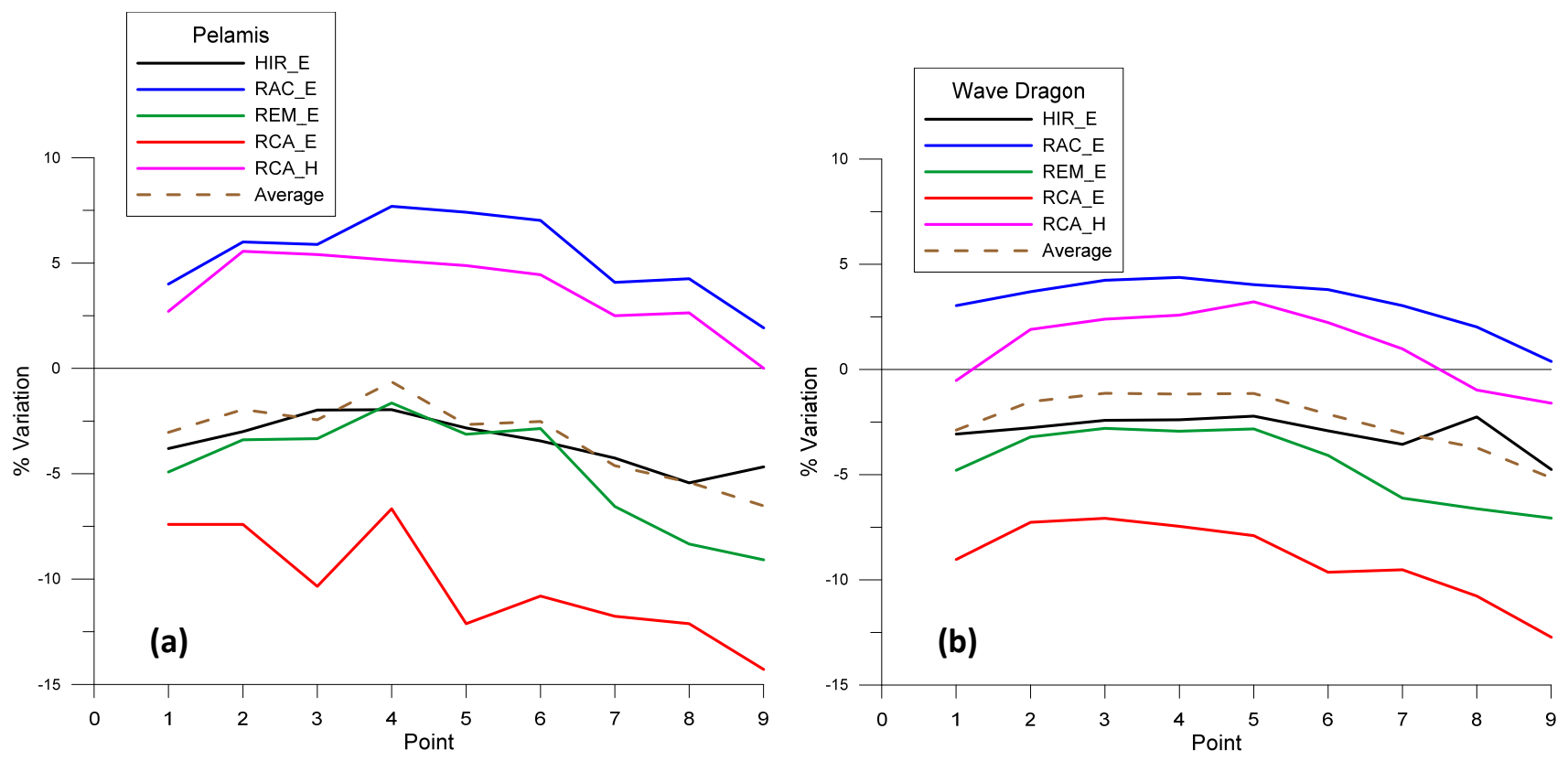

Fig. 12. Variation (\%) of wave energy output in future conditions with respect to the present at each point and for each model. (a): Pelamis WEC. (b): Wave Dragon WEC. Positive values indicate future increases of wave energy output, while negative values reflect future decreases. 


\section{Summary and conclusions}

The aim of this paper was to analyse how changes in wave patterns due to the effect of climate change can affect wave energy power and yield, focusing in Menorca (Spanish Mediterranean Sea). This area has been selected considering data availability and the power potential, which is one of the largest in the Mediterranean Sea, according to previous studies [14-15].

The study is based on the high-resolution wave projections developed by [20], which were obtained for two 30-year time periods (1971-2000 and 2071-2100) using 5 combinations of regional and global circulation models (RCMs and GCMs) forced by the A1B scenario from the $4^{\text {th }}$ assessment report of the IPCC [31]. Nine grid points located around the island have been selected, which cover its northern and eastern sides, where the most energetic potential is found [14-15]. At these points, the potential impact on wave energy resource is assessed by means of the present and future wave power and energy, directional average power, temporal variability and wave energy output given by 2 WECs whose power matrices are available. From the comparison between present and future conditions, the corresponding climate change signals are obtained for each RCM-GCM.

The multi-model ensemble gives rise to a slight future decrease in the annual wave energy for all locations, with a rate between $2.5 \%$ and $6 \%$. However, the inter-model variability is large and these ensemble values are not representative: three models give lower future wave energy (reductions between $5 \%$ and 15\%), while the other two project greater future wave energy (increases lower than $5 \%$ ). The reduction of wave energy projected in three models is due to decreases of wave height and period for both mean and extreme conditions. The increase of future wave energy given by 2 models is due to the greater wave height and period under storm conditions.

The directional and spatial distribution of the future wave energy is very similar to that of the present conditions. The most energetic areas remain in the NE and SE corners of the island.

With respect to the seasonal wave energy distribution the multi-model mean shows a clear future reduction in winter and autumn, a lower decrease during spring and spatial variability during summer (a tendency to increase in the northern part of the island whereas in the eastern part the negative trend is maintained like in the other seasons). Nevertheless the inter-model variability is very high with 2 models showing opposite trends compared to the other 3 , except in winter where 4 models give the same trend (wave energy reduction) and the fifth model projects negligible changes.

The analysis of the results also shows a consistent future reduction of the temporal variability, with lower values for coefficients MV and SV, considering either the multi-model ensemble or each single simulation. This is in agreement with the redistribution of energy throughout the year, which will allow a more regular wave energy yield over time.

The wave energy output given by the two analyzed WECs (Pelamis and Wave Dragon) also presents slight future reductions of the ensemble (average of the 5 models) although again there is a large inter-model variability, with 3 models giving decreases and 2 models giving increases, being Pelamis slightly more affected because it has its better performance at lower wave periods than Wave Dragon, and these lower periods are more frequent in the studied area.

Ultimately, the obtained results show that potential changes in wave conditions due to climate change can produce annual and seasonal variations in wave energy power and yield around Menorca. Nevertheless, although the ensemble of the 5 models entails a "negative" change (reduction of wave energy) the large inter-model variability, with 2 models offering opposite trends to the other 3 , indicates that the possibility of "positive" changes is non-negligible. 
Therefore, the results show two plausible future scenarios with an opposite trend in wave energy. Also it is important to point out that the two models projecting a rise have a different GCM, which was the main factor of variability in terms of the forcing mean wave climate. Since wave energy is largely affected by the extreme wave conditions, the inter-regional-model variability plays a greater role here. As mentioned in the Introduction, there is an agreement that the number of cyclones in the Mediterranean will decrease but there is still not consensus on whether the more intense cyclones will decrease or increase in both magnitude and frequency. And this is reflected in the uncertainty of the wave energy results presented in this study. Therefore further studies are needed to try to reduce the inter-model uncertainty for better decision-making (for example, by using updated climate projections that benefit from more accurate parameterizations implemented in the climate models). Additionally, other factors such as the greenhouse scenario and the internal climate variability need to be assessed to determine to which degree the impact on the future wave energy resource might be affected.

\section{Acknowledgements}

This study was funded by the research project "Desarrollo de una herramienta de alta resolución como soporte al diseño, colocación y explotación de instalaciones para energías marinas (DARDO)" funded by the Spanish Ministry of Economy and Competitiveness (grant no. ENE201238772-C02-02) and the European Union's Seventh Framework Programme through the grant to the budget of the Collaborative Project RISES-AM-, Contract FP7-ENV-2013-two-stage-603396.

The support of the Secretaria d'Universitats i Recerca del Dpt. d'Economia i Coneixement de la Generalitat de Catalunya (grant no. 2014SGR1253) is also acknowledged.

The authors gratefully acknowledge the four European research centers and institutions that have freely provided the atmospheric climate projection data sets used in this study: DMI (Danmarks Meteorologiske Institut, Denmark), KNMI (Koninklijk Nederlands Meteorologisch Instituut, The Netherlands), MPI (Max-Planck-Institut für Meteorologie, Germany) and SMHI (Sveriges Meteorologiska och Hydrologiska Institut, Sweden).

\section{References}

[1] Lenee-Bluhm P, Paasch R, Özkan-Haller HT. Characterizing the wave energy resource of the US Pacific Northwest. Renewable Energy 2011;36:2106-2119.

[2] Dalton GJ, Alcorn R, Lewis T. Case study feasibility analysis of the Pelamis wave energy convertor in Ireland, Portugal and North America. Renewable Energy 2010;35:443-455.

[3] Iglesias G, Carballo R. Wave power for La Isla Bonita. Energy 2010;35:513-521.

[4] Iglesias G, Carballo R. Wave resource in El Hierro -an island towards energy self-suficiency. Renewable Energy 2011;36:689-698.

[5] Sierra JP, González-Marco D, Sospedra J, Gironella X, Mösso C, Sánchez-Arcilla A. Wave energy resource assessment in Lanzarote (Spain). Renewable Energy 2013;55:480-489.

[6] Gonçalves M, Martinho P, Guedes Soares C. Assessment of wave energy in the Canary Islands. Renewable Energy 2014;68:774-784.

[7] Rusu E, Guedes Soares C. Wave energy pattern around the Madeira Islands. Energy 2012;45:771-785. 
[8] Rusu L, Guedes Soares C. Wave energy assessments in the Azores Islands. Renewable Energy 2012;45:183-196.

[9] Stopa JE, Cheung KF, Chen Y-L. Assessment of wave energy resources in Hawaii. Renewable Energy 2011;36:554-567.

[10] Stopa JE, Filipot J-F, Li N, Cheung KF, Chen Y-L, Vega L. Wave energy resources along the Hawaiian Island chain. Renewable Energy 2013;55:305-321.

[11] Chiu F-C, Wuang W-Y, Tiao W-C. The spatial and temporal characteristics of the wave energy resources around Taiwan. Renewable Energy 2013;52:218-221.

[12] Ortega S, Osorio AF, Agudelo P. Estimation of the wave power resource in the Caribbean Sea in areas with scarce instrumentation. Case study: Isla Fuerte, Colombia. Renewable Energy 2013;57:240-248.

[13] Vicinanza D, Contestabile P, Ferrante V. Wave energy potential in the north-west of Sardinia (Italy). Renewable Energy 2013;50:506-521.

[14] Sierra JP, Mösso C, González-Marco D. Wave energy resource assessment in Menorca (Spain). Renewable Energy 2014;71:51-60.

[15] Liberti L, Carillo A, Sannino G. Wave energy resource assessment in the Mediterranean, the Italian perspective. Renewable Energy 2013;50:938-949.

[16] Reeve DE, Chen Y, Pan S, Magar V, Simmonds DJ, Zacharioudaki A. An investigation of the impacts of climate change on wave energy generation: The Wave Hub, Cornwall, UK. Renewable Energy 2011;36:2404-2413.

[17] Harrison GP, Wallace AR. Sensitivity of wave energy to climate change. IEEE Transactions on Energy Conversion 2005;20:870-877.

[18] Mackay EBL, Bahaj AS, Chellenor PG. Uncertainty in wave energy resource assessment. Part 1: Historic data. Renewable Energy 2010;35:1792-1808.

[19] Mackay EBL, Bahaj AS, Chellenor PG. Uncertainty in wave energy resource assessment. Part 2: Variability and predictability. Renewable Energy 2010;35:1809-1819.

[20] Casas-Prat M, Sierra JP. Projected future wave climate in the NW Mediterranean Sea. Journal of Geophysical Research: Oceans 2013;118:3548-3568.

[21] Ulbrich U, Leckebusch GC, Pinto JG. Extra-tropical cyclones in the present and future climate: a review. Theoretical and Applied Climatology 2009;96:117-131.

[22] Bengtsson L, Hodges KI, Keenlyside N. Will extratropical storms intensify in a warmer climate? Journal of Climate 2009;22:2276-2301.

[23] Maheras P, Flocas HA, Patrikas I, Anagnostopoulou C. A 40 year objective climatology of surface ciclones in the Mediterranean región: spatial and temporal distribution. International Journal of Climatology 2001;21:109-130.

[24] Campins J, Genovés A, Picornell MA, Jansà A. Climatology of Mediterranean cyclones using the ERA-40 dataset. International Journal of Climatology 2011;31:1596-1614.

[25] Lionello P, Dalan F, Elvini E. Cyclones in the Mediterranean region: the present and the doubled CO2 climate scenarios. Climate Research 2002;22:147-159. 
[26] Lionello P, Boldrin U, Giorgi F. Future changes in cyclone climatology over Europe as inferred from a regional climate simulation. Climate Dynamics 2008;30:657-671.

[27] Donat MG, Leckebusch GC, Wild S, Ulbrich U. Future changes in European winter storm losses and extreme wind speeds inferred from GCM and RCM multi-model simulations. Natural Hazards and Earth System Sciences 2011;11:1351-1370.

[28] Pinto JG, Ulbrich U, Leckebusch GC, Spangehl T, Zacharias S. Changes in storm track and cyclone activity in three SRES ensemble experiments with the ECHAM5/MPI-OM1 GCM. Climate Dynamics 2007;29:195-210.

[29] Donat M, Leckebusch G, Pinto J, Ulbrich U. European storminess and associated circulation weather types: Future changes deduced from a multi-model ensemble of GCM simulations. Climate Research 2010;42:27-43.

[30] Booij N, Ris RC, Holthuijsen LH. A third-generation wave model for coastal regions: 1. Model description and validation. Journal of Geophysical Research 1999;104:7649-7666.

[31] IPCC. Fourth Assessment Report of the Intergovernmental Panel of Climate Change. Synthesis Report. IPCC 2007.

[32] Cornett AM. A global wave energy resource assessment. In International Offshore and Polar Engineering Conference, Vancouver, Canada 2008; pp. 318-326.

[33] Boronowski S, Wild P, Rowe A, van Kooten GC. Integration of wave power in Haida Gwaii. Renewable Energy 2010;35:2415-2421.

[34] Carballo R, Sanchez M, Ramos V, Fraguela JA, Iglesias G. Intra-annual wave resource characterization for energy exploitation: a new decision-aid tool. Energy Conversion and Management 2015;93:1-8.

[35] Henderson R. Design, simulation and testing of a novel hydraulic power take-off system for the Pelamis wave energy converter. Renewable Energy 2006;31:271-283.

[36] Kofoed JP, Frigaard P, Friis-Madsen E, Sørensen HC. Prototype testing of the wave energy converter wave dragon. Renewable Energy 2006;31:181-189.

[37] Rusu L, Onea F. Assessment of the performance of various wave energy converters along the European continental coasts. Energy 2015;82:889-904.

[38] Silva D, Rusu E, Guedes Soares C. Evaluation of various technologies for wave energy conversion in the Portuguese nearshore. Energies 2013;6:1344-1364.

[39] Rusu E, Onea F. Estimation of the wave energy conversion efficiency in the Atlantic Ocean close to the European islands. Renewable Energy 2016;85:687-703.

[40] Sierra JP, Martín C, Mösso C, Mestres M, Jebbad R. Wave energy potential along the Atlantic coast of Morocco. Renewable Energy 2016;96:20-32.

[41] Rute Bento A, Rusu E, Martinho P, Guedes Soares C. Assessment of the changes induced by a wave energy farm in the nearshore wave conditions. Computers \& Geosciences 2014;71:50-61.

[42] Iglesias G, Carballo R. Wave farm impact: the role of farm-to-coast distance. Renewable Energy 2014;69:375-385.

[43] Ris RC, Holthuijsen LH, Booij N. A third-generation wave model for coastal regions. 2. Verification. Journal of Geophysical Research 1999;104:7667-7681. 